\title{
Understanding and optimizing health-related quality of life and physical functional capacity in idiopathic pulmonary fibrosis
}

This article was published in the following Dove Press journal:

Patient Related Outcome Measures

17 May 2016

Number of times this article has been viewed

\author{
Amy L Olson \\ Kevin K Brown \\ Jeffrey J Swigris \\ Department of Medicine Division of \\ Pulmonary Medicine, Interstitial Lung \\ Disease Program and Autoimmune \\ Lung Center, National Jewish Health, \\ Denver, CO, USA
}

\begin{abstract}
Idiopathic pulmonary fibrosis (IPF) is a relentlessly progressive pulmonary disease characterized by the insidious onset of shortness of breath due to parenchymal scarring. As IPF progresses, breathlessness worsens, physical functional capacity declines, and health-related quality of life (HRQL) - the impact of health or disease on a person's satisfaction with their overall station in life - deteriorates. These two inextricably linked variables - breathlessness and physical functional capacity - are strong drivers of HRQL. With the emergence of new and prospective therapies for IPF, it is more important than ever to be able to accurately and reliably assess how IPF patients feel and function. Doing so will promote the development of novel interventions to target impairments in these areas and ensure that the field is capable of assessing the effect of therapeutics interventions on these critically important patient-centered outcomes.
\end{abstract}

Keywords: idiopathic pulmonary fibrosis, health-related quality of life, functional status

\section{Introduction}

Idiopathic pulmonary fibrosis (IPF) is a relentlessly progressive disease that results in progressive scar formation within the lung parenchyma. As IPF progresses, its hallmark symptom, breathlessness, worsens; physical functional capacity declines; and health-related quality of life (HRQL) - the impact of health or disease on a person's satisfaction with their overall station in life - deteriorates. Respiratory failure is the cause of death in the majority of patients with IPF. ${ }^{1}$

Two drugs were recently approved for IPF by the US Food and Drug Administration (FDA); each was shown in a Phase III trial to slow physiologic progression. ${ }^{2,3}$ Despite these outstanding achievements, there is still no cure for IPF - it remains a progressive, debilitating, and life-shortening disease. Although physiologic variables provide useful information to clinicians about a patient's disease status (and they are frequently used as outcome measures in clinical trials), these parameters fail to fully capture how IPF patients feel and function. ${ }^{4}$

In IPF patients, breathlessness limits physical functional capacity, or the ability to perform basic activities and participate in life situations. These two inextricably linked variables - shortness of breath and physical functional capacity - are strong drivers of HRQL in patients with IPF. By better understanding the effects of IPF on these two variables, attempts can be made to target specifically affected domains thereby improving overall HRQL. This review summarizes our current knowledge on the assessment of HRQL (and the domain physical functional capacity) in patients with IPF and highlights the need for ongoing research in this field.
National Jewish Health, 1400 Jackson

Street, FI07, Denver, Colorado 80206

USA

Tel +I 303398 I62I

$\mathrm{Fax}+\mathrm{I} 3032702440$

Email olsona@njhealth.org
Patient Related Outcome Measures 2016:7 29-35

(c) (i) () 2016 Olson et al. This work is published and licensed by Dove Medical Press Limited. The full terms of this license are available at https://www.dovepress.com/terms. (c) BY NC php and incorporate the Creative Commons Attribution - Non Commercial (unported, v3.0) License (http:///creativecommons.org/licenses/by-nc/3.0/). By accessing the work you hereby accept the Terms. Non-commercial uses of the work are permitted without any further permission from Dove Medical Press Limited, provided the work is properly attributed. For you hereby accept the Terms. Non-commercial uses of the work are permitted without any further permission from Dove Medical
permmercial use of this work, please see paragraphs 4.2 and 5 of our Terms (https://www.dovepress.com/terms.php).
Dovepress

http://dx.doi.org/10.2/47/PROM.S74857 


\section{Health-related quality of life}

HRQL is a term that conveys an individual's contentment with aspects of life that maybe affected by health., ${ }^{4,5}$ The measurement of HRQL has been defined as the "quantification" of the impact of health or disease (and all that it entails, including formal and informal care as well as therapeutics) on a patient's life. ${ }^{6}$

HRQL instruments can be generic (ie, not intended for a specific disease), with the advantage of being useful in multiple settings and in either ill or well populations. Generic instruments are likely to be less sensitive to change than disease- or condition-specific instruments when administered to patients with a specific condition, such as IPF. In contrast, because they capture unique aspects of disease (eg, symptoms) that generic instruments do not, disease- or condition-specific instruments are likely to be more sensitive to change.

\section{Assessing HRQL in IPF}

Generic and respiratory-specific instruments (developed for patients with obstructive lung disease) have been used to assess HRQL in patients with IPF. In this section, we focus on the most frequently used generic and disease-specific HRQL instruments used in IPF research and briefly discuss the instruments that are being developed specifically for IPF.

\section{The Medical Outcomes Study 36-Item Short Form}

The Medical Outcomes Study 36-Item Short Form (SF-36) is a generic questionnaire that was developed for use in clinical practice and research, health policy evaluations, and general population surveys. ${ }^{7}$ It includes eight domains: 1) physical functioning (PF), 2) role limitations due to physical problems, 3) bodily pain (BP), 4) general health perceptions $(\mathrm{GH}), 5)$ social functioning $(\mathrm{SF}), 6)$ role limitations due to emotional problems, 7) vitality (VT), and 8) general mental health (MH). In addition, the first four domains can be combined to yield a physical component summary and the last four can be combined to yield a mental component summary. 8,9

In several studies, investigators have used SF-36 to evaluate HRQL in IPF. Martinez et al compared SF-36 scores between 34 controls matched these to 34 Brazilian IPF patients who were followed in a specialized clinic at a teaching hospital. ${ }^{10}$ While there was no difference in scores from the BP domain (as would be expected, because IPF is not a physically painful disease), scores from all other domains were significantly lower for patients compared to controls. The domains that were most compromised in the IPF patients included PF (limitations in physical activity) and pulmonary rehabilitation (PR) (the extent to which physical health interferes with work or other daily activities). ${ }^{11}$ Dyspnea was most strongly correlated with $\mathrm{PF}$ domain scores $(r=0.78, P<0.001)$ but was also significantly correlated with scores from the $\mathrm{GH}$, VT, SF, and MH domains. Similar results were found by other investigators in their cross-sectional studies. ${ }^{12-14}$

In a longitudinal study, Tomika et al observed that scores from the PF and GH domains were sensitive to change in status identified by decline in pulmonary physiology or gas exchange. ${ }^{15}$ Like other researchers who conducted subsequent studies, these investigators observed that IPF patients who needed supplemental oxygen $\left(\mathrm{O}_{2}\right)$ had greater impairments in several SF-36 domains than IPF patients who did not need $\mathrm{O}_{2}$. The change over time in SF-36 scores deemed meaningful to patients - also known as the minimum important difference (MID) - in IPF ranges from 2 to 4 points. ${ }^{16}$

Available data suggest that the SF-36 possesses some validity for capturing HRQL in IPF patients.

\section{The St George Respiratory Questionnaire}

The St George Respiratory Questionnaire (SGRQ) is an "obstructive lung disease-specific questionnaire" that has been used to assess HRQL in IPF. ${ }^{17}$ This questionnaire has 50 items split into three domains: 1) the "symptoms" domain asks about the frequency of cough, sputum production, dyspnea, wheeze, and severity of attacks of chest trouble; 2) the "activity" domain inquires about activities causing or limited by breathlessness; and 3) the "impacts" domain queries the effect of the chest condition overall; on employment; on feelings of embarrassment, fear, or panic, and being in control of health; on the need for medication; and on expectations for health. In contrast to the SF-36, higher scores on the individual domains or on the total score indicate worse HRQL. Many cross-sectional studies have used the SGRQ to measure HRQL in IPF patients. In several of these studies, like the PF domain from the SF-36, scores from the "activity" domain of the SGRQ correlate strongly with dyspnea. Certain studies have yielded longitudinal data, and in a recent literature review of these studies, the authors examined the overall psychometric performance of the SGRQ in IPF. ${ }^{18}$ In the following paragraphs, we highlight some of the data from these studies.

In 2000, De Vries et al administered the SGRQ to IPF patients and found that compared to the scores from the "impacts" or "symptoms" domains or the SGRQ "total score", mean scores from the "activity" domain were highest (representing worse HRQL). ${ }^{19}$ The same scoring pattern 
has been observed in several other studies, thus highlighting the prevalence of breathlessness and limitations in physical functional capacity among IPF patients. ${ }^{20-22}$ Verma et al studied 137 Canadian IPF patients and observed that "activity" domain scores were the highest among all SGRQ scores, and IPF patients scores on all four SGRQ domains (symptoms, activity, impacts, and total) were significantly higher than the scores from age-matched population normal values. In a multivariate linear regression analysis, the only clinical variable that correlated with all four SGRQ scores was the distance covered during a 6-minute walk test (6MWD) a marker of submaximal exercise and, arguably, a surrogate for physical functional capacity. ${ }^{23}$ Peng et al studied 68 IPF patients who completed the SGRQ at baseline and at 6 months. ${ }^{24}$ Changes in dyspnea and changes in distance covered during a timed walk test correlated with changes in the "activity" and "impacts" domains and changes in the SGRQ total score, but not with changes in the "symptom" domain. These data highlight the important contribution of PF to HRQL in patients with IPF and raise questions about the validity of the "symptom" domain of this obstructive lung disease-specific instrument. ${ }^{23,24}$

In a review of 30 published manuscripts, Swigris et $\mathrm{al}^{18}$ concluded that the internal consistency of the "activity" and "impacts" domains and the total score from the SGRQ was excellent, while the internal consistency of the symptoms domain was moderate - this may be due to the fact that symptoms frequently occurring in patients with obstructive lung diseases (eg, wheeze) do not necessarily occur in patients with IPF. Validity of the SGRQ was supported by moderate to strong correlations between its scores and scores from other patient-reported outcomes and with physiological variables and exercise capacity. They found evidence that changes in SGRQ domain and total scores could discriminate IPF patients with mild, moderate, and severe diseases. Estimates for the SGRQ MID range from 5 to 8 points. ${ }^{18}$

Face validity notwithstanding, and although many questions about the psychometric properties of the SGRQ in IPF remain to be answered, available data suggest that the SGRQ performs reasonably well in samples of IPF patients. ${ }^{18}$

\section{Interstitial lung disease (ILD)-specific HRQL questionnaires}

An ILD-specific HRQL instrument has been developed, and results from subsequent studies support its validity for assessing HRQL in IPF. The King's Brief Interstitial Lung Disease (K-BILD) health status questionnaire was developed in 173 patients with ILD (49 had IPF). The final version of the K-BILD questionnaire consists of 15 items in three domains (breathlessness and activities, chest symptoms, and psychological). Studies showed that its internal consistency was high, with a Cronbach's $\alpha$ of 0.94 for the total score, and supported its concurrent validity (correlation with the SGRQ was very strong $[r=0.90]$ and with vital capacity was moderate $[r=0.50])$. The K-BILD questionnaire was repeatable over 2 weeks, with intra-class correlation coefficients for domains and total scores that ranged from 0.86 to $0.94 .^{25}$ The MID for the K-BILD is 8 units. ${ }^{26}$ Although the K-BILD was developed for patients with any form of ILD, it is unclear how the K-BILD performs in an IPF-only cohort.

\section{IPF-specific HRQL questionnaires}

Two IPF-specific HRQL instruments have been developed. ATAQ-IPF (A Tool to Assess QOL in IPF, version 1) was developed after focus group and in-depth interviews were conducted with IPF patients to determine their perceptions of living with the disease. Additional research on ATAQ-IPF is needed and currently underway. ${ }^{27}$

An IPF-specific version of the SGRQ (SGRQ-I) was developed by using SGRQ response data from a multicenter, placebo-controlled trial for IPF. ${ }^{28}$ Yorke et al used a systematic, statistically based method (Rasch analysis) on baseline SGRQ response data to develop the IPF-specific version. ${ }^{22}$ Reliability and validity of the SGRQ-I in IPF were acceptable and comparable to the original SGRQ. Like ATAQ-IPF, further studies are needed to assess the psychometric properties of this instrument. ${ }^{22}$

\section{How to optimize HRQL in IPF patients Pulmonary rehabilitation}

Two randomized, controlled trials of PR have been conducted on patients with IPF. ${ }^{29,30}$ Nishiyama et al randomized 30 IPF patients to either the intervention (10 weeks of PR) or the control group. Compared to the control group $(n=15)$, subjects who completed PR $(n=13)$ had marked improvements in the SGRQ total score $(-6.1 ; 95 \% \mathrm{CI}:-11.7-0.5)$ and in 6MWD (mean difference: $46.3 \mathrm{~m}$; 95\% CI:8.3-84.4 m). ${ }^{29}$ Holland et al randomized 57 ILD subjects (34 with IPF) to either 8 weeks of PR or weekly telephone support. ${ }^{30}$ Of those randomized to PR, 80\% completed the program. PR improved HRQL in the dyspnea and fatigue domains of the Chronic Respiratory Questionnaire, but of the eight domains of the SF-36, only scores from the VT domain improved significantly (3.58 points; $95 \%$ CI: $0.44-5.72$ ). PR also led to a greater than $30 \mathrm{~m}$ improvement in 6MWD. ${ }^{30}$ Results from other studies suggest PR improves dyspnea and fatigue. ${ }^{31,32}$ 
In a subgroup of IPF studies from a meta-analysis of PR in ILD, PR improved 6MWD (weighted mean difference [WMD]: $35.6 \mathrm{~m}, 95 \% \mathrm{CI}: 16.0-55.2 \mathrm{~m}$ ), $\mathrm{O}_{2}$ consumption (WMD: $1.46 \mathrm{~mL} / \mathrm{kg} / \mathrm{min}(-1), 95 \%$ CI: $0.54-2.39 \mathrm{~mL} / \mathrm{kg} / \mathrm{min}(-1))$, dyspnea, and quality of life. ${ }^{33}$

Home-based PR programs also appear to improve HRQL and functional capacity in patients with IPF. ${ }^{34,35}$ Ozalevli et al found that a 12-week, home-based PR improved several HRQL domains (assessed by the SF-36), dyspnea, and 6MWD. ${ }^{34}$ Rammaert et al conducted a similar study and observed similar results. ${ }^{35}$ Thus, like center-based programs, home-based PR programs appear to benefit patients with IPF, and given the constraints of the disease, time and distance required to travel to a center that offers $\mathrm{PF}$, home-based programs may be easier for IPF patients to complete.

\section{Novel interventions}

Lindell et al developed and tested a 6-week program (termed PRISM: Program to Reduce Idiopathic Pulmonary Fibrosis Symptoms and Improve Management) designed to improve HRQL, symptoms, stress, and anxiety in IPF patients and their caregivers. ${ }^{36}$ Although patients did not experience improvements in outcomes after completing the program, results suggested that PRISM lowered stress in caregivers $(P=0.018)$. Qualitative debriefing suggested positive benefits for IPF patients, including feelings of being less isolated, being able to put their disease into perspective, and they valued the opportunity to participate in research. Further investigation is needed to determine if disease management programs can improve HRQL and to determine which instruments should be used to assess response.

\section{Recently approved FDA therapies}

In May 2014, the results of two drug trials in IPF were published. ${ }^{2,3}$ In the two trials of nintedanib, HRQL was measured using the SGRQ. In the first trial, there was no significant between-groups difference in the adjusted mean change in the total SGRQ score from baseline to week 52 . In the second study, there was a significantly smaller increase in the total SGRQ score at 52 weeks in the nintedanib group (suggesting less deterioration in HRQL) versus placebo (2.80 vs 5.48 points; difference: -2.69 ; $95 \%$ CI: -4.95 to -0.43 ; $P=0.02$ ). In the pirfenidone trial, HRQL was not measured. At week 52, there was no significant between-groups difference in dyspnea. However, at week 52 fewer subjects in the pirfendone group than the placebo group $(25.9 \%$ vs $35.7 \%, P=0.04$ ) met the composite endpoint of a decrease in $6 \mathrm{MWD}$ of $50 \mathrm{~m}$ or more or death. As more novel IPF therapies undergo investigation (there are several in company pipelines across the world), it will be imperative to assess endpoints that are meaningful to patients (including HRQL and physical functional capacity).

\section{Physical functional capacity}

There are multiple reasons why IPF patients suffer impairments in physical functional capacity. ${ }^{37}$ To date, there is no gold standard to assess physical functional capacity -

"or the ability to perform basic activities and participate in life situations" - in IPF. ${ }^{38}$ While a patient's aerobic capacity (cardiopulmonary system) is often thought of as the main driver of functional status, both physical performance (ie, the ability to integrate the cardiopulmonary and skeletal muscle systems to achieve optimum function) and psychosocial factors (such as confidence and perceived ability) play roles in determining overall functional status. ${ }^{39}$

\section{The 6-minute walk test}

In IPF, 6MWD has been repeatedly used as a surrogate of physical functional capacity and as an outcome measure in a number of trials of IPF-targeted therapies. Advantages of the 6MWD include that it is easy to perform and inexpensive. ${ }^{40} 6 \mathrm{MWD}$ correlates with peak $\mathrm{O}_{2}$ uptake obtained via a cardiopulmonary exercise test, ${ }^{41}$ and it can help stage IPF severity and predict mortality in IPF patients. ${ }^{42,43}$

$\mathrm{du}$ Bois et al used data from 822 subjects enrolled in trials of interferon gamma 1-b for IPF to assess the reliability, validity, and responsiveness of the 6MWD and to triangulate its MID. ${ }^{43,44}$ These investigators found that the 6MWD had acceptable inter-test reliability (coefficient=0.83, $P<0.001$ ) and data supported its construct validity. A decline in $6 \mathrm{MWD}>50 \mathrm{~m}$ over 24 weeks was associated with a fourfold increase in the risk of death at 1 year, and the MID was estimated to be between 24 and $45 \mathrm{~m}$. Despite these findings, 6MWD has limitations when used as a marker of functional status: it provides no insight into the facets or mechanisms of limitation (and thus provides no direction for how to target therapeutic interventions), and most importantly, 6MWD does not provide insight about the overall day-to-day functional status of a patient. ${ }^{45-47}$ For example, although PR can improve 6MWD, it is unclear if such improvements translate to better overall physical functional capacity outside the test environment.

Thus, although 6MWD is touted as a measure of physical functional capacity, it is best regarded as a measure 
of submaximal exercise. Emerging data from the chronic obstructive pulmonary disease (COPD) literature highlight how poorly 6MWD reflects day-to-day activity in COPD patients. ${ }^{48,49}$ An informative, accurate tool to measure dayto-day physical functional capacity of IPF patients is desperately needed. Novel approaches used to measure physical functional capacity could provide valuable insight into the facets and severity of physical functional impairment in IPF patients. Such tools should be sensitive to change over time and may allow targeted therapies to improve functioning. ${ }^{39}$

\section{Functional status questionnaires}

Although never rigorously studied in IPF, researchers have raised concerns that self-reports of physical function (such as the instrumental activities of daily living [ADL], ADL, and the Rosow-Breslau scale) do not provide specific and enough information about the type of impairment a patient endures, and these measures may lack sensitivity to change. . $^{395}$

Kozu et al investigated the relationships between dyspnea grade (as measured by the Medical Research Council scale) and ADL, ${ }^{51-53}$ peripheral muscle force, HRQL (via the SF-36), and physiologic and gas exchange parameters in IPF patients $(n=65)$. Predictably, as dyspnea increased, each domain of the SF-36 (except BP), as well as 6MWD, ADL scores, and strength (as measured by hand force grip and quadriceps force, assessed by dynamometer) all declined.

\section{The cardiopulmonary exercise test}

The cardiopulmonary exercise test measures maximal exercise capacity, or maximal oxygen consumption $\left(\mathrm{VO}_{2 \max }\right)$, an integrated measure of cardiovascular, respiratory, and neuromuscular function. ${ }^{54}$ Patients with IPF clearly have exercise limitation, and severe limitation is associated with a poor prognosis. ${ }^{55}$ However, similar to $6 \mathrm{MWD}$, it is unclear how decreased exercise tolerance translates to day-to-day functional status, or how it informs the development of therapeutic interventions.

\section{Novel assessments of functional status}

While data from self-report questionnaires, 6MWD, and cardiopulmonary exercise testing all suggest that physical functional capacity is impaired in IPF patients, each of these modalities has shortcomings. In the following paragraphs, we describe two tools that arguably yield more useful information.

\section{Accelerometers}

Accelerometers are multisensory devices, worn on the body, and yield a number of parameters of physical activity, such as 1) number of steps, 2) walking distance, 3) time spent at different magnitudes of movement, 4) physical activity-related energy expenditure, and 5) total energy expenditure. ${ }^{56}$ In patients with COPD, among an array of candidate variables, physical activity, as assessed by an accelerometer, was the strongest predictor of all-cause mortality. ${ }^{57}$ Research is needed to determine if - as in COPD - accelerometers can assess limitations, provide targets for intervention, and assess response to therapies in patients with IPF.

\section{The Continuous-Scale Physical Functional Performance Test}

Our group recently published data from a study in which we used the continuous-scale physical function performance test (CS-PFP) to determine physical functional capacity in patients with IPF. ${ }^{58}$ The CS-PFP test directly assesses ADL and has been shown to be reliable, valid, and responsive to change in the healthy aged and in patients with any of several diseases. ${ }^{39,58-63}$ The CS-PFP test is a series of 10 tasks that simulate everyday-life activities required to maintain independence. It includes tasks such as carrying a bag of groceries (including ascent and descent of a public transportation platform), transferring laundry from a washer to a dryer, and simulating getting in and out of a bathtub. Each task is scored on time, distance achieved, and/or weight carried during a task. The CS-PFP has five domain scores (upper body strength, lower body strength, upper body flexibility, balance and coordination, and endurance) and a composite score of these domains. Each score ranges from 0 to 100 based on the lower and upper extremes of performance; thus, higher scores reflect greater physical functional capacity.

Sixteen IPF subjects completed a baseline CS-PFP test and repeated it 1 week later. We found that the test-retest reliability $(0.84, P=0.003)$ and internal consistency (Cronbach's $\alpha=0.91)$ of the CS-PFP were excellent. IPF subjects had significantly worse total CS-PFP scores than age-matched controls (46.0 \pm 11.1 vs $58.7 \pm 12.5, P=0.001$ ), as well as significantly reduced lower body strength and endurance. The total score correlated moderately strongly with pulmonary physiology and gas exchange - markers of disease severity and with HRQL domains that assess PF. For example, the CS-PFP most strongly correlated with the PF domain from the SF-36 and the "activity" domain from the SGRQ, thus supporting the construct validity of the CS-PFP as a measure of physical functional capacity. Further assessment of this test in IPF patients is warranted. 


\section{Conclusion}

In patients with IPF, HRQL is impaired in multiple domains. Two of the strongest drivers of HRQL impairment are dyspnea and limitations in physical functional capacity. While PR appears to improve both dyspnea and 6MWD, it is unclear if improvements in 6MWD translate into better day-to-day physical functional capacity. Unfortunately, even in this new era of FDA-approved therapies for the treatment of IPF, the majority of IPF patients will die from the disease and suffer as the disease progresses. With the emergence of new therapies, it is even more important to accurately and reliably assess how patients feel and function with this disease, to devise novel interventions to target impairment, and to ensure that we understand the impact of therapeutics on patient-centered outcomes.

\section{Disclosure}

The authors report no conflict of interest in this work.

\section{References}

1. Raghu G, Collard H, Egan JJ, et al. An official ATS/ERJ/JRS/ALAT statement: idiopathic pulmonary fibrosis: evidence-based guidelines for diagnosis and management. Am J Respir Crit Care Med. 2011;183(6):788-824.

2. King TE Jr, Williamson ZB, Castro-Bernardini S, et al. A phase 3 trial of pirfenidone in patients with idiopathic pulmonary fibrosis. $N$ Engl J Med. 2014;370(22):2083-2092.

3. Richeldi L, du Bois RM, Raghu G, et al. Efficacy and safety of nintedanib in idiopathic pulmonary fibrosis. $N$ Engl J Med. 2014;370(22):2071-2082.

4. Guyatt GH, Feeny DH, Patrick DL. Measuring health-related quality of life. Ann Intern Med. 1993;118(8):622-629.

5. Belkin A, Swigris JJ. Health-related quality of life in idiopathic pulmonary fibrosis: where are we now? Curr Opin Pulm Med. 2013;19(5):474-479.

6. Jones PW. Quality of life measurement for patients with diseases of the airways. Thorax 1991;46(9):676-682.

7. Ware JE Jr, Sherbourne CD. The MOS 36-item short-form health survey (SF-36). I. Conceptual framework and item selection. Med Care. 1992;30(6):473-483.

8. McHorney C, Ware JE Jr, Lu J, et al. The MOS 36-item Short Form Health Survey (SF-36): III. Tests of data quality, scaling assumptions, and reliability across diverse patient groups. Med Care. 1994;32(1):40-66.

9. Bousquet J, Knani J, Dhivert H, et al. Quality of life in asthma: I. Internal consistency and validity of the SF-36 questionnaire. Am J Respir Crit Care Med. 1994;149(2 Pt 1):371-375.

10. Martinez TY, Pereira CAC, dos Santos ML, Ciconelli RM, Guimarães SM, Martinez JA. Evaluation of the short-form 36-item questionnaire to measure health related quality of life in patients with idiopathic pulmonary fibrosis. Chest. 2000;117(6):1627-1632.

11. McHorney C, Ware JE Jr, Raczek A. The MOS 36-Item Short-Form Health Survey (SF-36): II. Psychometric and clinical tests of validity in measuring physical and mental health constructs. Med Care. 1993;31(3):247-263.

12. Baddini Martinez JA, Martinez TY, Lovetro Galhardo FP, de Castro Pereira CA. Dyspnea scales as a measure of health-related quality of life in patients with idiopathic pulmonary fibrosis. Med Sci Monit. 2002;8(6):CR405-CR410.
13. Ohno S, Nakazawa S, Kobayashi A, Bando M, Sugiyama Y. Reassessment of the classification of the severity in idiopathic pulmonary fibrosis using SF-36 questionnaire. Intern Med. 2005;44(3):196-199.

14. Clark M, Cooper B, Singh S, Cooper M, Carr A, Hubbard R. A survey of nocturnal hypoxaemia and health related quality of life in patients with cryptogenic fibrosing alveolitis. Thorax. 2001;56(6):482-486.

15. Tomika H, Imanaka K, Hashimoto K, Iwasaki H. Health-related quality of life with idiopathic pulmonary fibrosis: cross-sectional and longitudinal study. Intern Med. 2007;46(18):1533-1542.

16. Swigris JJ, Brown KK, Behr J, et al. The SF-36 and SGRQ: validity and first look at minimum important difference in IPF. Respir Med. 2010;104(6):296-304.

17. Jones PW, Quirk FH, Baveystock CM. The St George's Respiratory Questionnaire. Respir Med. 1991;85 (Suppl B):25-31.

18. Swigris JJ, Esser D, Conoscenti CS, Brown KK. The psychometric properties of the St George's Respiratory Questionnaire (SGRQ) in patients with idiopathic pulmonary fibrosis: a literature review. Health Qual Life Outcomes. 2014;12(2):124-127.

19. De Vries J, Seebregts A, Drent M. Assessing health status and quality of life in idiopathic pulmonary fibrosis: which measure should be used? Respir Med. 2000;94(3):273-278.

20. Nishiyama O, Taniguchi H, Kondoh Y, et al. Health-related quality of life in patients with idiopathic pulmonary fibrosis. What is the main contributing factor? Respir Med. 2005;99(2):408-414.

21. Zimmermann CS, Carvalho CRF, Silveira KR, et al. Comparison of two questionnaires which measure the health related quality of life in idiopathic pulmonary fibrosis patients. Braz J Med Biol Res. 2007;40(2):179-187.

22. Yorke J, Jones PW, Swigris JJ. Development and validity testing of an IPF-specific version of the St George's Respiratory Questionnaire. Thorax. 2010;65(10):921-926.

23. Verma G, Marras T, Chowdhury N, Singer L. Health-related quality of life and 6 minute walk distance in patients with idiopathic pulmonary fibrosis. Can Respir J. 2011;18(5):283-287.

24. Peng S, Li Z, Kang J, Hou X. Cross-sectional and longitudinal construct validity of the Saint George's Respiratory Questionnaire in patients with IPF. Respirology. 2008;13(6):871-879.

25. Patel AS, Siegert RJ, Brignall K, et al. The development and validation of the King's Brief Interstitial Lung Disease (K-BILD) health status questionnaire. Thorax. 2012;67(9):804-810.

26. Patel AS, Siegert RJ, Keir GJ, et al. The minimal important difference of the King's Brief Interstitial Lung Disease Questionnaire (K-BILD) and forced vital capacity in interstitial lung disease. Respir Med. 2013;107(9):1438-1443.

27. Swigris JJ, Wilson SR, Green KE, Sprunger DB, Brown KK, WamboldtFS. Development of the ATAQ-IPF: a tool to assess quality of life in IPF. Health Qual Life Outcomes. 2010;8:77.

28. King TE Jr, Behr J, Brown KK, et al. BUILD-1: a randomized placebocontrolled trial of bosentan in idiopathic pulmonary fibrosis. Am J Respir Crit Care Med. 2008;177(1):75-81

29. Nishiyama O, Kondoh Y, Kirmura T, et al. Effects of pulmonary rehabilitation in patients with idiopathic pulmonary fibrosis. Respirology. 2008;13(3):394-399.

30. Holland AE, Hill CJ, Conron M, Munro P, McDonald CF. Short term improvement in exercise capacity and symptoms following exercise training in interstitial lung disease. Thorax. 2008;63(6):549-554.

31. Kozu R, Senjyu H, Jenkins SC, Mukae H, Sakamoto N, Kohno S. Differences in response to pulmonary rehabilitation in idiopathic pulmonary fibrosis. Respiration. 2011;81(3):196-205.

32. Swigris JJ, Fairclough DL, Morrison M, et al. Benefits of pulmonary rehabilitation in idiopathic pulmonary fibrosis. Respir Care. 2011;56(6):783-789.

33. Dowman L, Hill CJ, Holland AE. Pulmonary rehabilitation for interstitial lung disease. Cochrane Database Syst Rev. 2014;10:CD006322.

34. Ozalevli S, Karaali HK, Ilgin D, Ucan ES. Effect of home-based pulmonary rehabilitation in patients with idiopathic pulmonary fibrosis. Multidisciplinary Respir Med. 2010;5(1):31-37. 
35. Rammaert B, Leroy S, Cavestri B, Wallaert B, Grosbois JM. Effect of home-based pulmonary rehabilitation in idiopathic pulmonary fibrosis. Rev Mal Respir. 2009;26(3):275-282. French.

36. Lindell KO, Olshansky E, Song MK, et al. Impact of a diseasemanagement program on symptom burden and health-related quality of life in patients with idiopathic pulmonary fibrosis and their care partners. Heart Lung. 2010;39(4):304-313.

37. Swigris JJ, Brown KK, Make BJ, Wamboldt FS. Pulmonary rehabilitation in idiopathic pulmonary fibrosis: a call for continued investigation Respir Med. 2008;102(12):1675-1680.

38. National Committee on Vital and Health Statistics. Classifying and reporting functional status; 1998. Available from: www.ncvhs.hhs. gov/010617rp.pdf. Accessed January 29, 2012.

39. Cress ME, Buchner DM, Questad KA, Esselman PC, deLateur BJ, Schwartz RS. Continuous-scale physical functional performance in health older adults: a validation study. Arch Phys Med Rehabil. 1996;77(12):1243-1250.

40. ATS Committee on Proficiency Standards for Clinical Pulmonary Function Laboratories. ATS statement: guidelines for the six-minute walk test. Am J Respir Crit Care Med. 2002;166(1):111-117.

41. Ross RM, Murthy JN, Wollak ID, Jackson AS. The six minute walk test accurately estimates mean peak oxygen uptake. BMC Pulm Med. 2010;10:31.

42. Flaherty KR, Andrei AC, Murray S, et al. Idiopathic pulmonary fibrosis: prognostic values of changes in physiology and six-minute walk test. Am J Respir Crit Care Med. 2006;174(7):803-809.

43. du Bois RM, Weycker D, Albera C, et al. Six-minute-walk test in idiopathic pulmonary fibrosis: test validation and minimal clinically important difference. Am J Respir Crit Care Med. 2011;183(9):1231-1237.

44. King TE, Albera C, Bradford WZ, et al. Effect of interferon gamma-1b on survival in patients with idiopathic pulmonary fibrosis (INSPIRE): a multicentre, randomised, placebo-controlled trial. Lancet. 2009;374(9685):222-228.

45. Azuma A, Nukiwa T, Tsuboi E, et al. Double-blind, placebo controlled trial of pirfenidone in patients with idiopathic pulmonary fibrosis. Am J Respir Crit Care Med. 2005;171(9):1040-1047.

46. Elpern EH, Stevens D, Kesten S. Variability in performance of the time walk test in pulmonary rehabilitation programs. Chest. 2000;118(1):98-105.

47. Heresi GA, Dweik RA. Strengths and limitations of the six-minutewalk test: a model biomarker study in idiopathic pulmonary fibrosis [comment]. Am J Respir Crit Care Med. 2011;183(9):1122-1124.

48. Fastenau A, van Schayck OC, Gosselink R, Aretz KC, Muris JW. Discrepancy between functional exercise capacity and daily physical activity: a cross-sectional study in patients with mild to moderate COPD. Prim Care Respir J. 2013;22(4):425-430.

49. Waschki B, Kirsten AM, Holz O, et al. Disease progression and changes in physical activity in patients with chronic obstructive pulmonary disease. Am J Respir Crit Care Med. 2015;192(3):295-306.
50. Fried LP, Ettinger WH, Lind B, Newman AB, Gardin J. Physical disability in older adults: a physiologic approach. Cardiovascular Health Study Research Group. J Clin Epidemiol. 1994;47(7):747-760.

51. Kozu R, Jenkins S, Senjyu H. Evaluation of activity limitation in patients with idiopathic pulmonary fibrosis grouped according to Medical Research Council Dyspnea Grade. Arch Phys Med Rehabil. 2014;95(5):950-955.

52. Spector WD, Katz S, Murphy JB, Fulton JP. The hierarchical relationship between activities of daily living and instrumental activities of daily living. J Chronic Dis. 1987;40(6):481-489.

53. Ando M, Mori A, Esaki H, et al. The effect of pulmonary rehabilitation in patients with post-tuberculosis lung disorder. Chest. 2003;123(6):1988-1995.

54. American Thoracic Society, American College of Chest Physicians. ATS/ACCP statement on cardiopulmonary exercise testing. Am J Respir Crit Care Med. 2003;167(2):211-277.

55. Fell C, Liu LX, Motika C, et al. The prognostic value of cardiopulmonary exercise testing in idiopathic pulmonary fibrosis. Am J Respir Crit Care. 2009; 179(5):402-407.

56. Nakayama M, Bando M, Araki K, et al. Physical activity in patients with idiopathic pulmonary fibrosis. Respirology. 2015;20(4):640-646.

57. Waschki B, Kirsten A, Holz O, et al. Physical activity is the strongest predictor of all-cause mortality in patients with COPD: a prospective cohort study. Chest. 2011;140(2):331-342.

58. Olson AL, Swigris JJ, Belkin A, et al. Physical functional capacity in idiopathic pulmonary fibrosis: performance characteristics of the continuous-scale physical function performance test. Expert Rev Respir Med. 2015;9(3):361-367.

59. Cress ME, Petrella JK, Moore TL, Schenkman ML. Continuous-scale physical functional performance test: validity, reliability, and sensitivity of data for the short version. Phys Ther. 2005;85(4):323-335.

60. Cress ME, Buchner DM, Questad KA, Esselman PC, deLateur BJ, Schwartz RS. Exercise: effects on physical functional performance in independent older adults. J Gerontol A Biol Sci Med Sci. 1999;54(5):M242-M248.

61. Brochu M, Savage P, Lee M, et al. Resistance training in older women with coronary heart disease: a randomized controlled trial. J Appl Physiol (1985). 2002;92(2):672-678.

62. Hearty TM, Schlenkman ML, Kohrt WM, Cress ME. Continuous scale physical functional performance test: appropriateness for middle-aged adults for middle-aged adults with and without Parkinson's disease. J Neurol Phys Ther. 2007;31(2):64-70.

63. Gary RA, Cress ME, Higgins MK, Smith AL, Dunbar SB. A combined aerobic and resistance exercise program improves physical functional performance in patients with heart failure: a pilot study. $J$ Cardiovasc Nurs. 2012;27(5):418-430.
Patient Related Outcome Measures

\section{Publish your work in this journal}

Patient Related Outcome Measures is an international, peer-reviewed, open access journal focusing on treatment outcomes specifically relevant to patients. All aspects of patient care are addressed within the journal and practitioners from all disciplines are invited to submit their work as well as healthcare researchers and patient support groups.

\section{Dovepress}

The manuscript management system is completely online and includes a very quick and fair peer-review system. Visit http://www.dovepress. com/testimonials.php to read real quotes from published authors. 